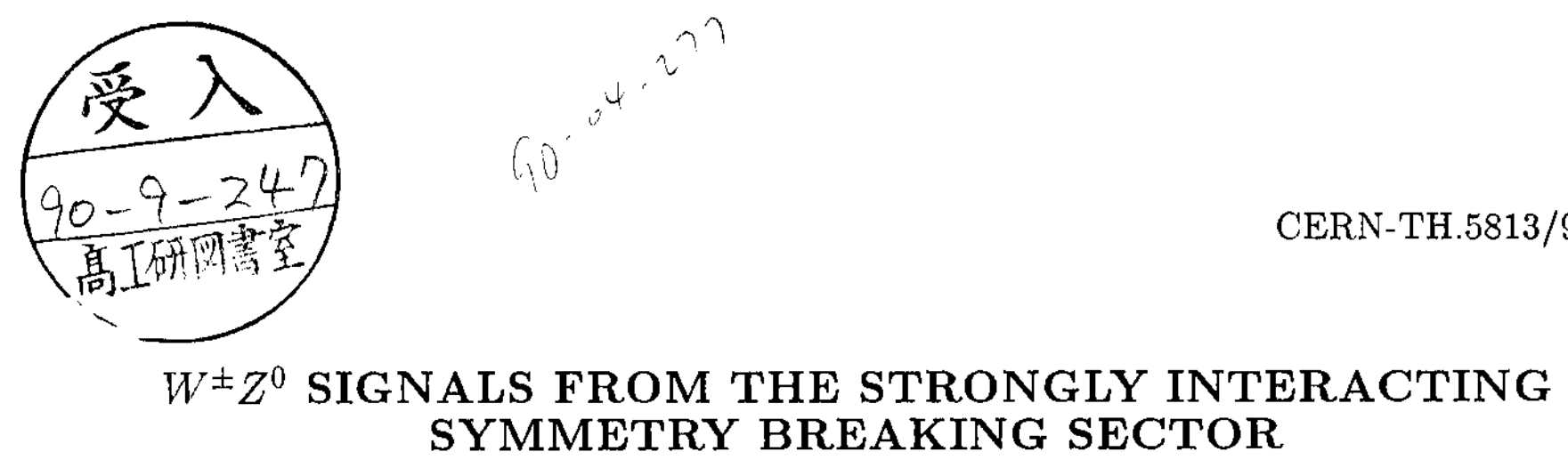

\author{
Antonio DOBADO ${ }^{1}$
}

Maria J. HERRERO ${ }^{2}$

CERN, CH-1211 Geneva, Switzerland

and

\title{
Juan TERRON
}

Departamento de Fisica Teorica de la Universidad Autonoma de Madrid, 28049 Madrid, Spain

\begin{abstract}
We study the possibilities of unraveling the underlying dynamics of the symmetry breaking sector through the scattering of longitudinal weak bosons in $p p$ collisions. $W^{ \pm} Z^{0}$ channels are considered in the context of a general approach based on chiral perturbation theory, supplemented by a unitarization procedure. The channels considered here are the relevant ones for symmetry breaking sector dynamics such as technicolor, where a $I=J=1$ resonance appears in the spectrum. Direct $\mathrm{WZ}$ production from quark annihilation via $\rho_{T C}-\mathrm{W}$ mixing is also considered and compared with WZ production from the WZ fusion mechanism.
\end{abstract}

CERN-TH.5813/90

July 1990

\footnotetext{
${ }^{1}$ On leave of absence from Departamento de Fisica Teorica de la Universidad Complutense de Madrid. 28040 Madrid, Spain

${ }^{2}$ On leave of absence from Departamento de Fisica Teorica de la Universidad Autonoma de Madrid, 28049 Madrid, Spain
} 


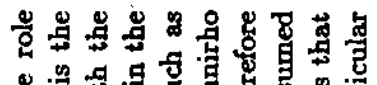

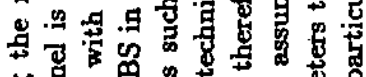

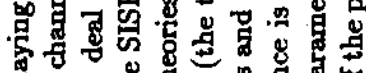

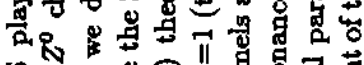

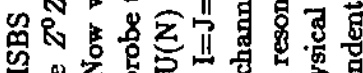

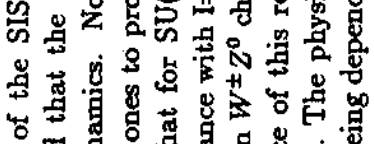

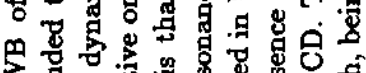

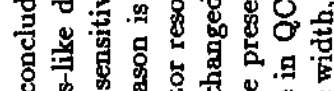

5

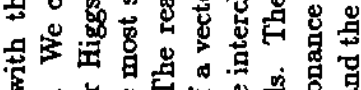

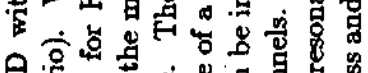

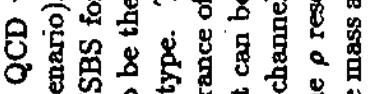

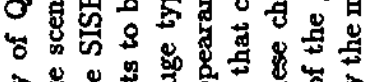

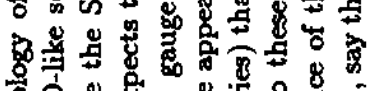

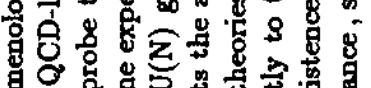

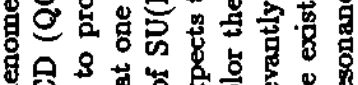

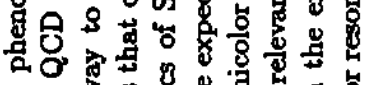

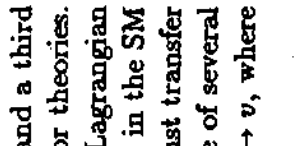

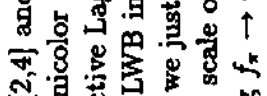

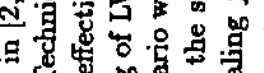

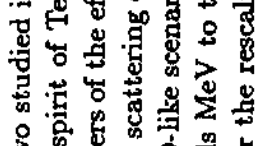
(5)

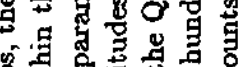

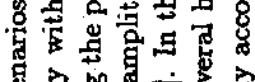

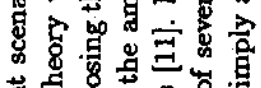

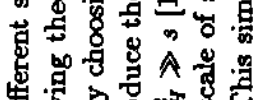

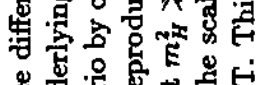

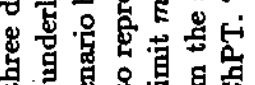

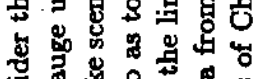

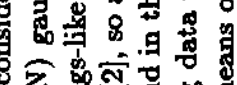

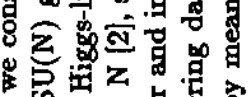

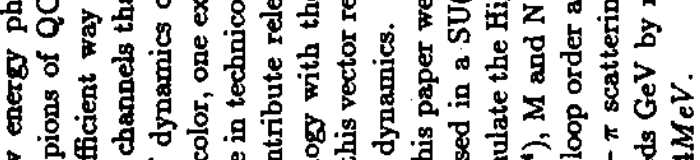

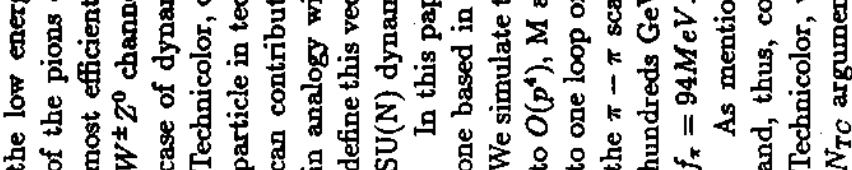

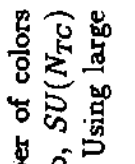

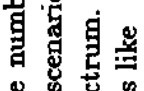

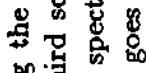

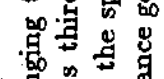

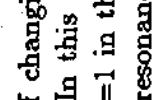

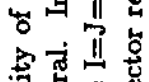

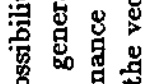
2.905

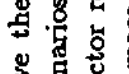

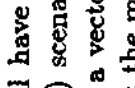
言家.

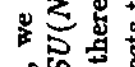
5. 8 ช.:

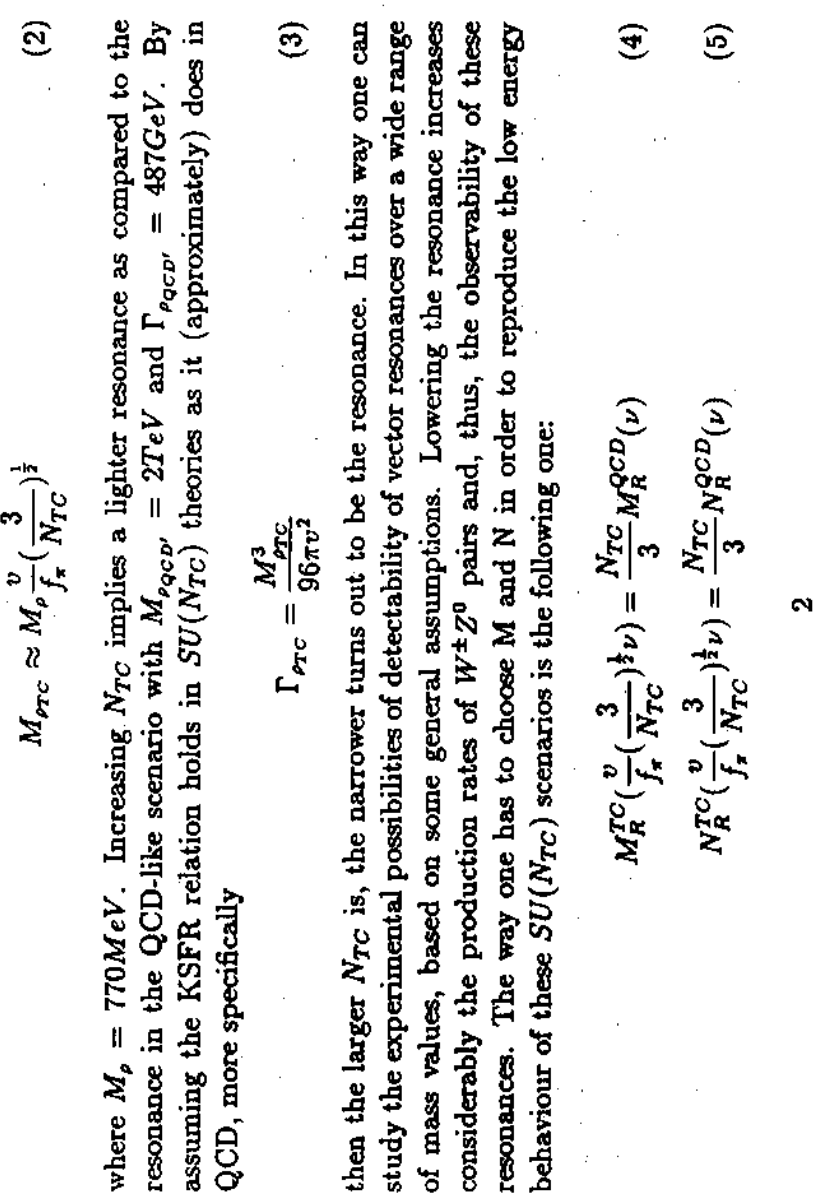

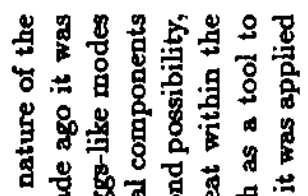

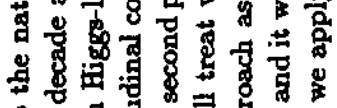

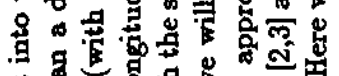

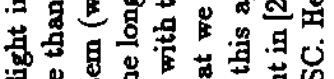

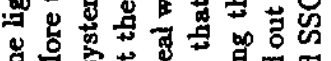

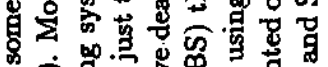

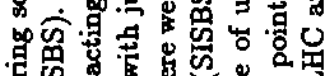

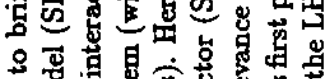

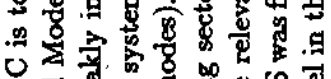

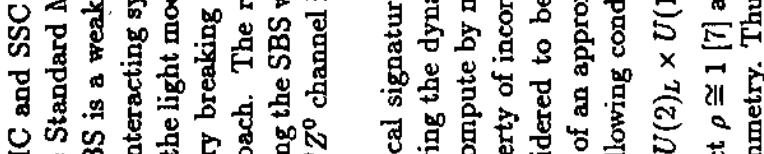

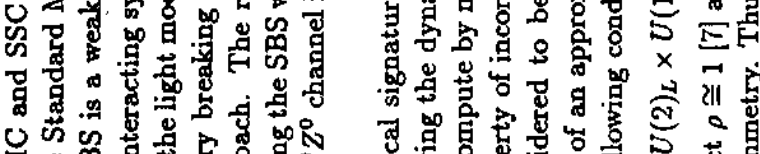

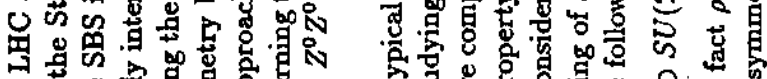

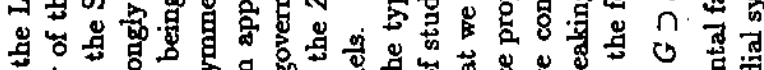
3. 9.

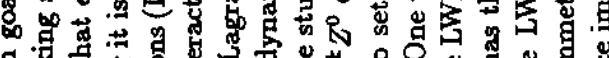

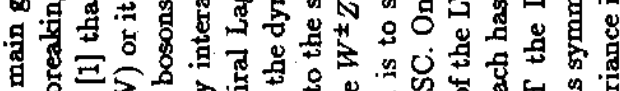

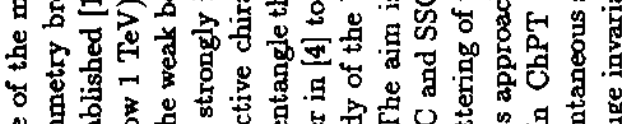

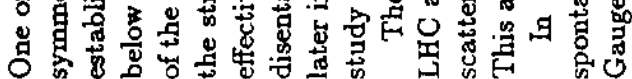



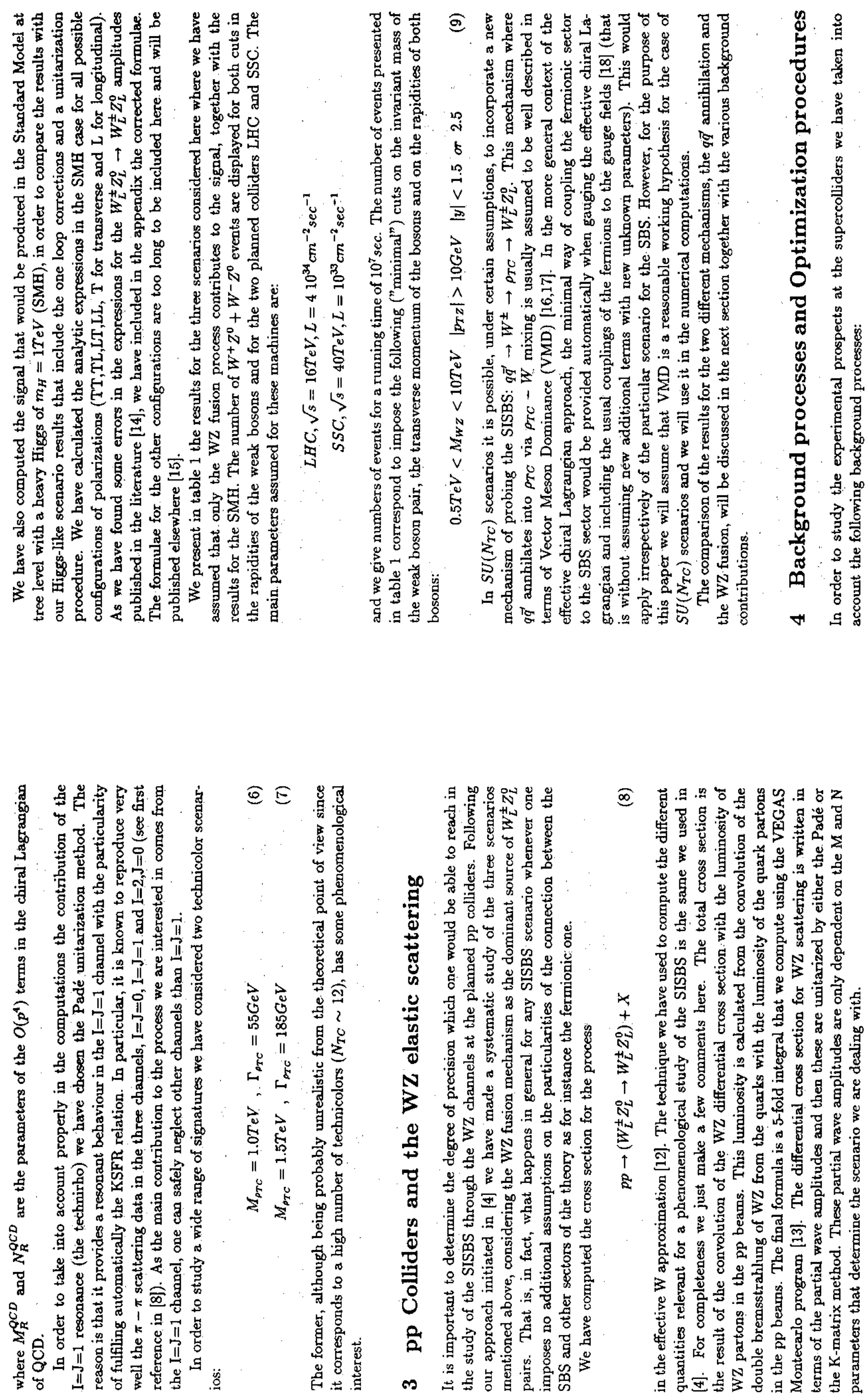


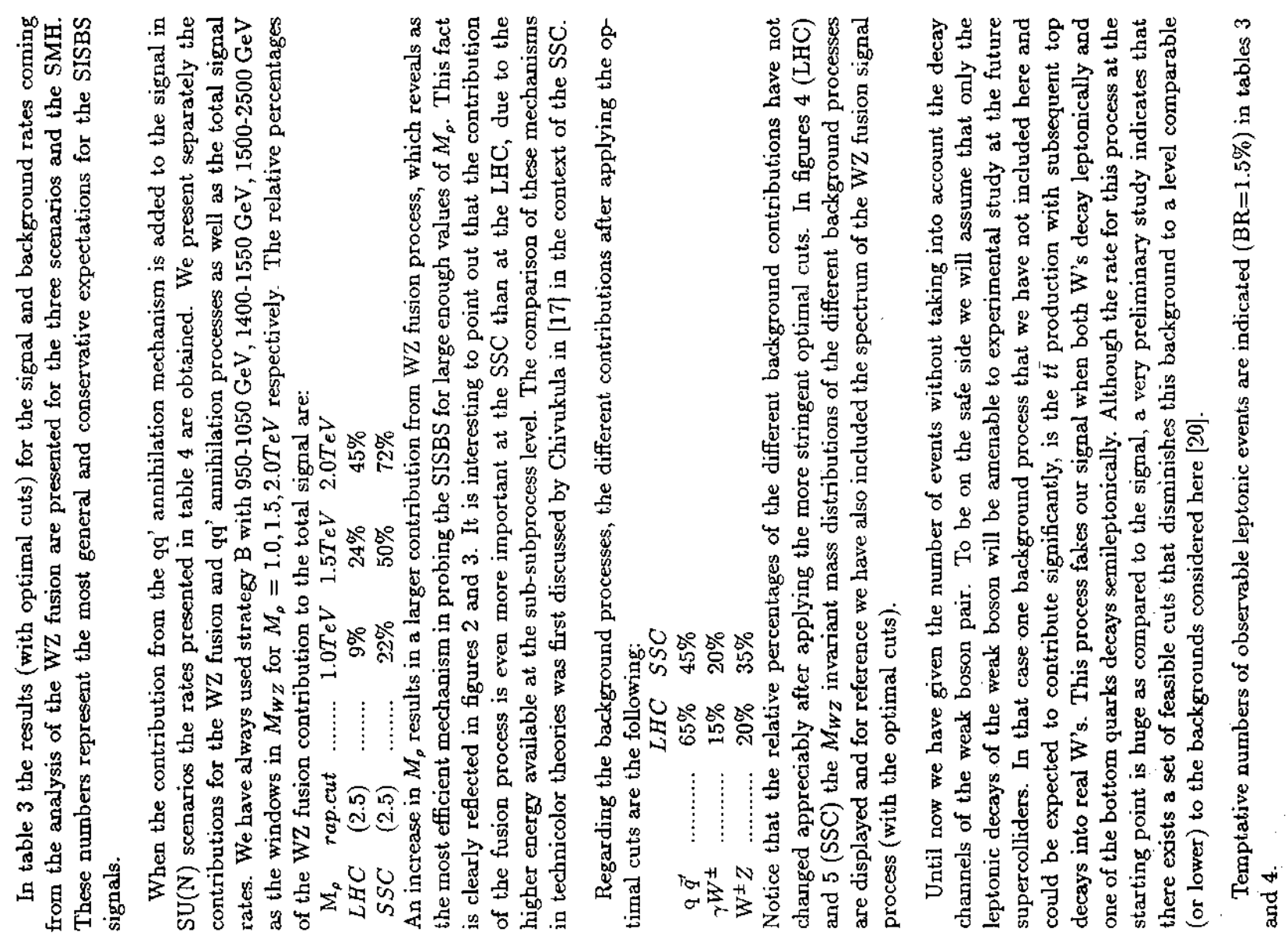

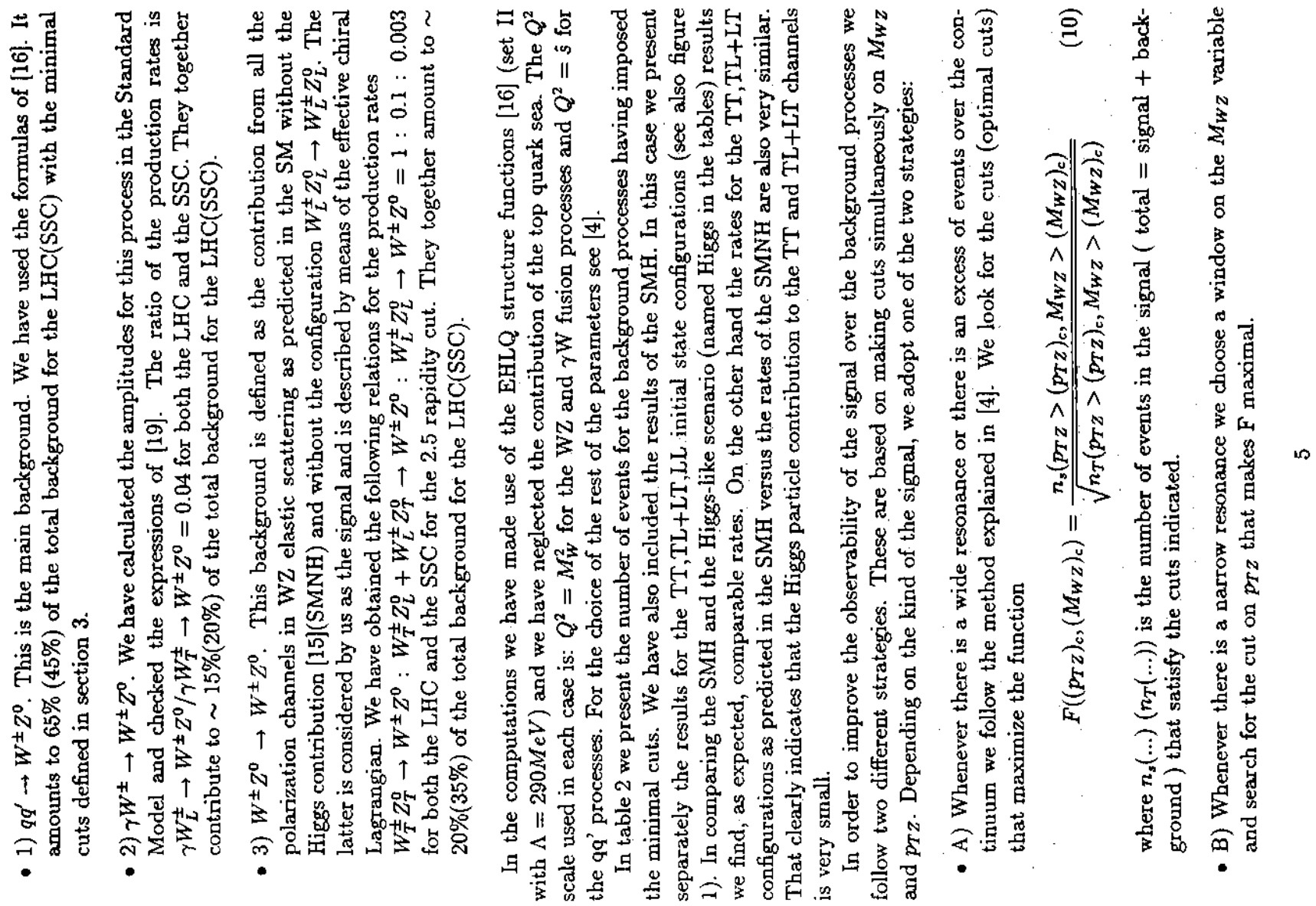



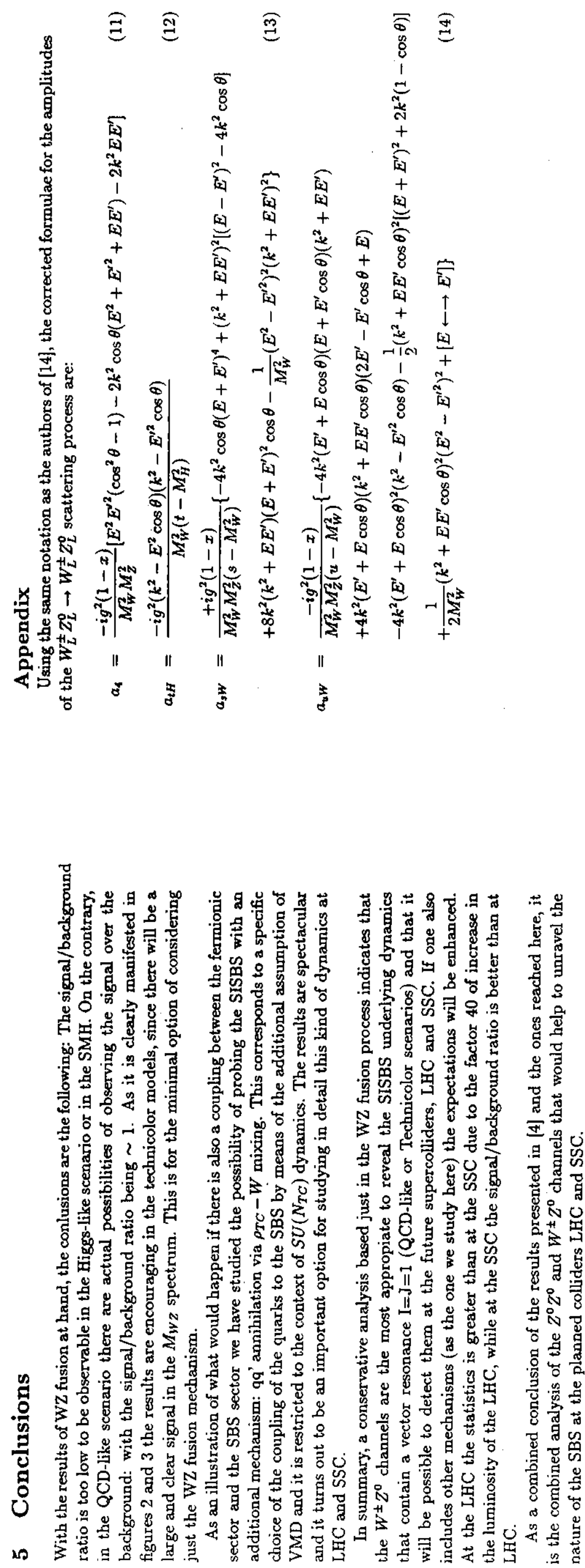

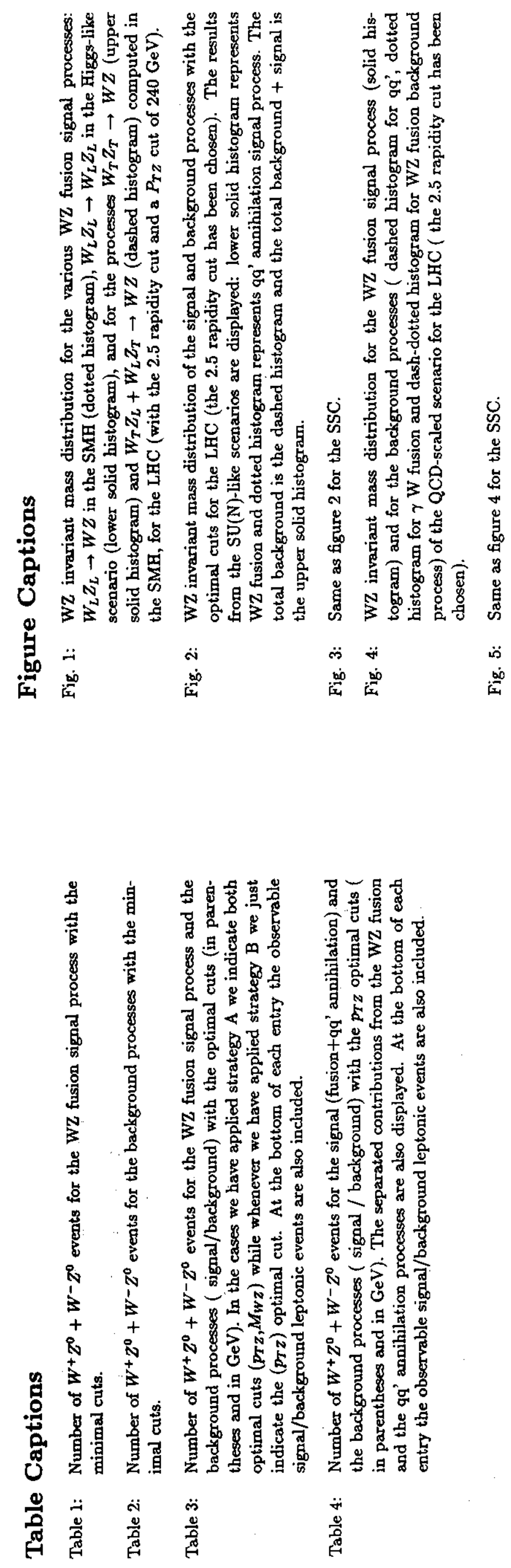

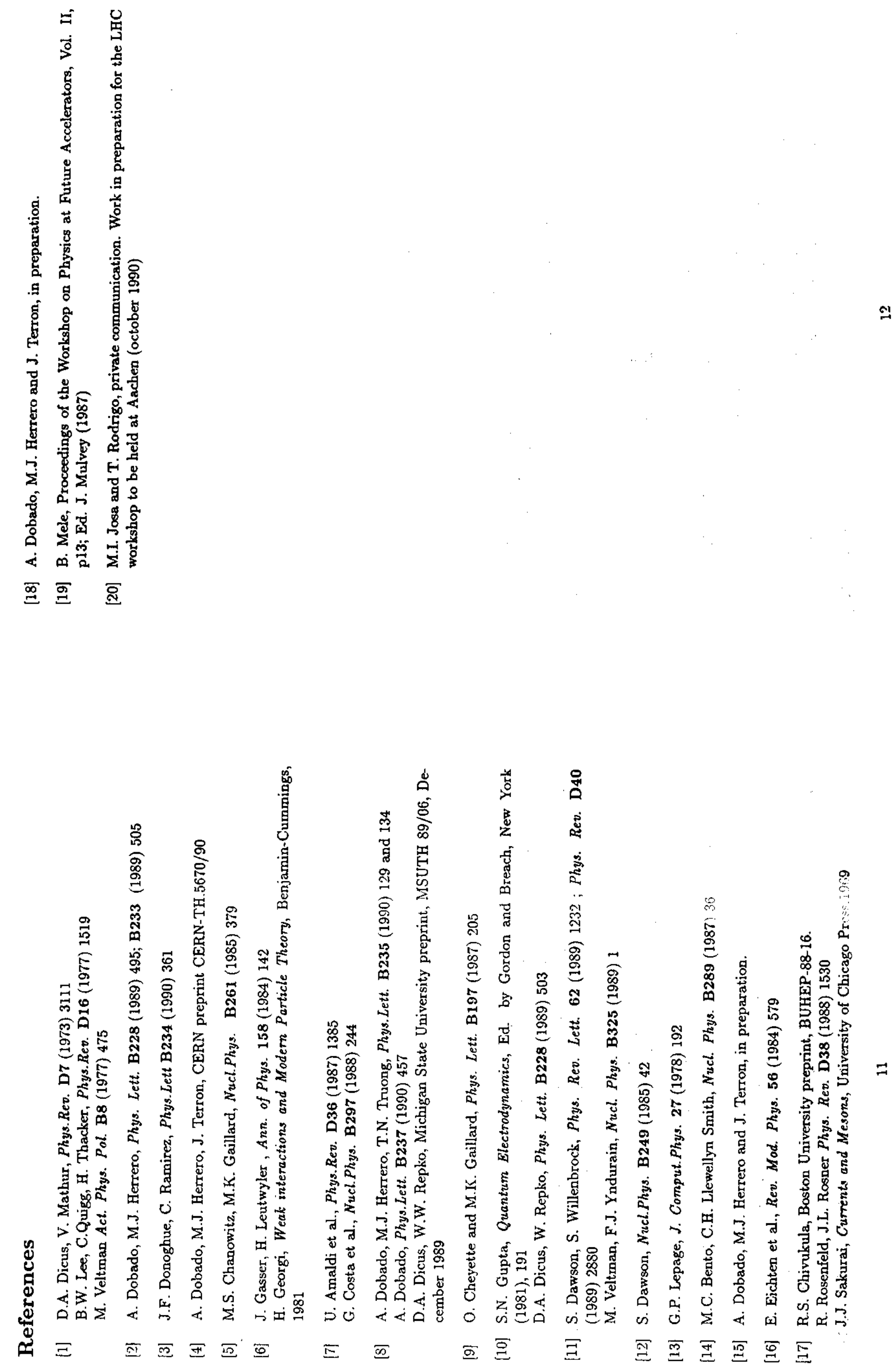


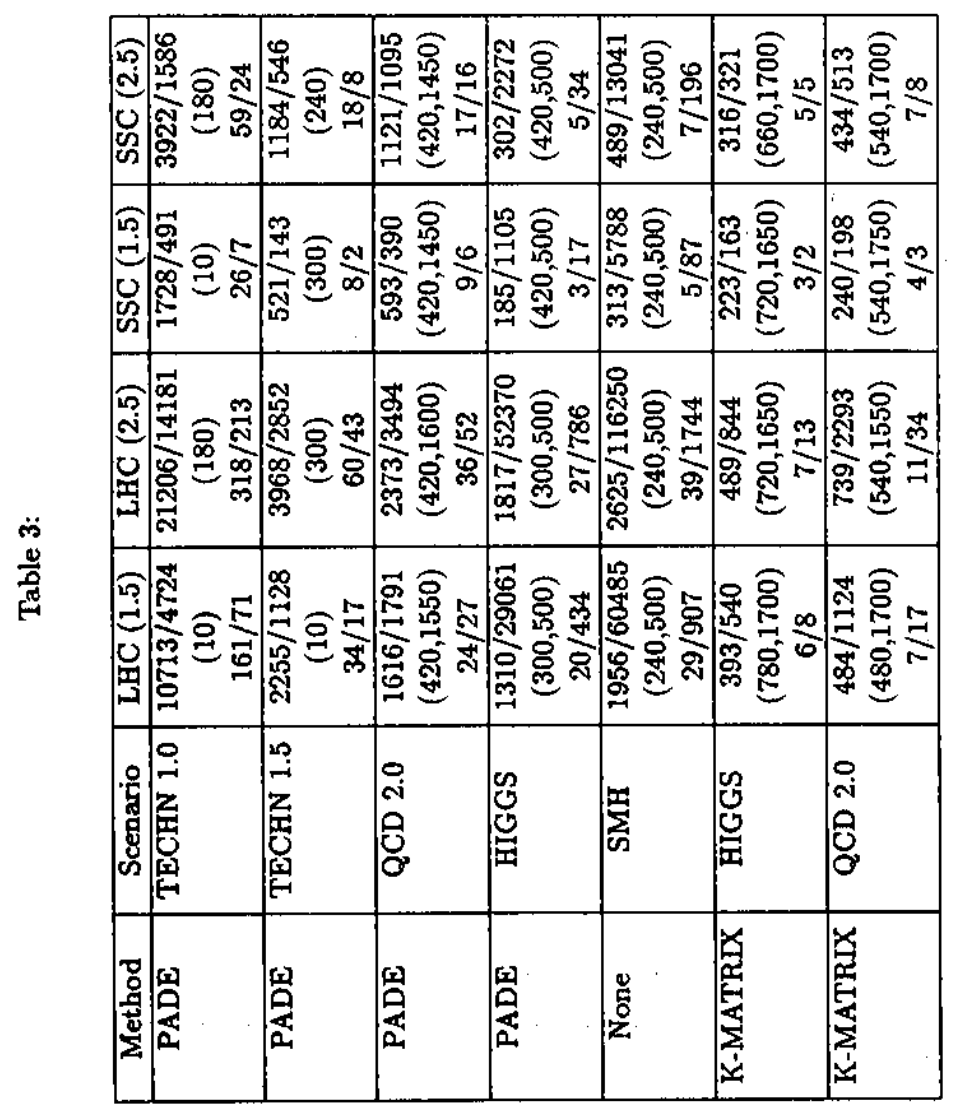
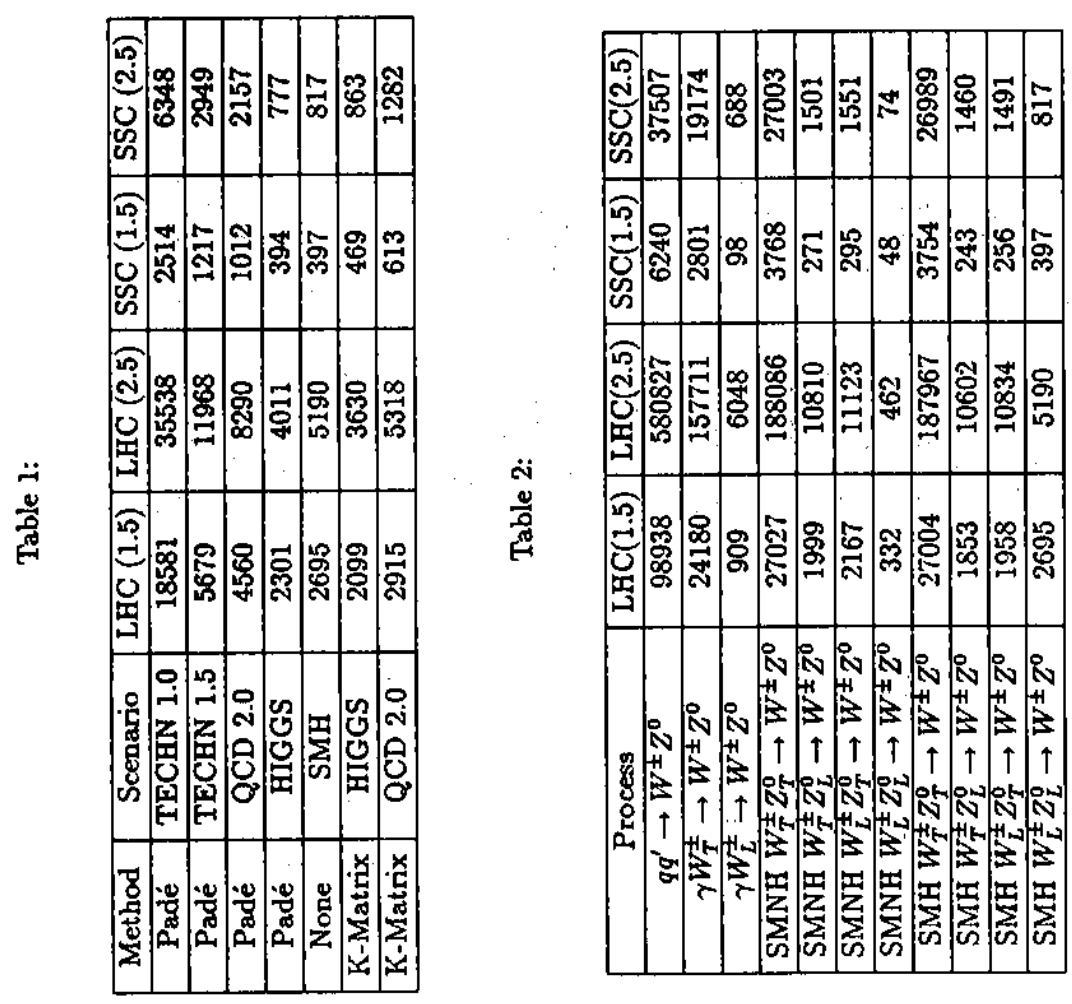

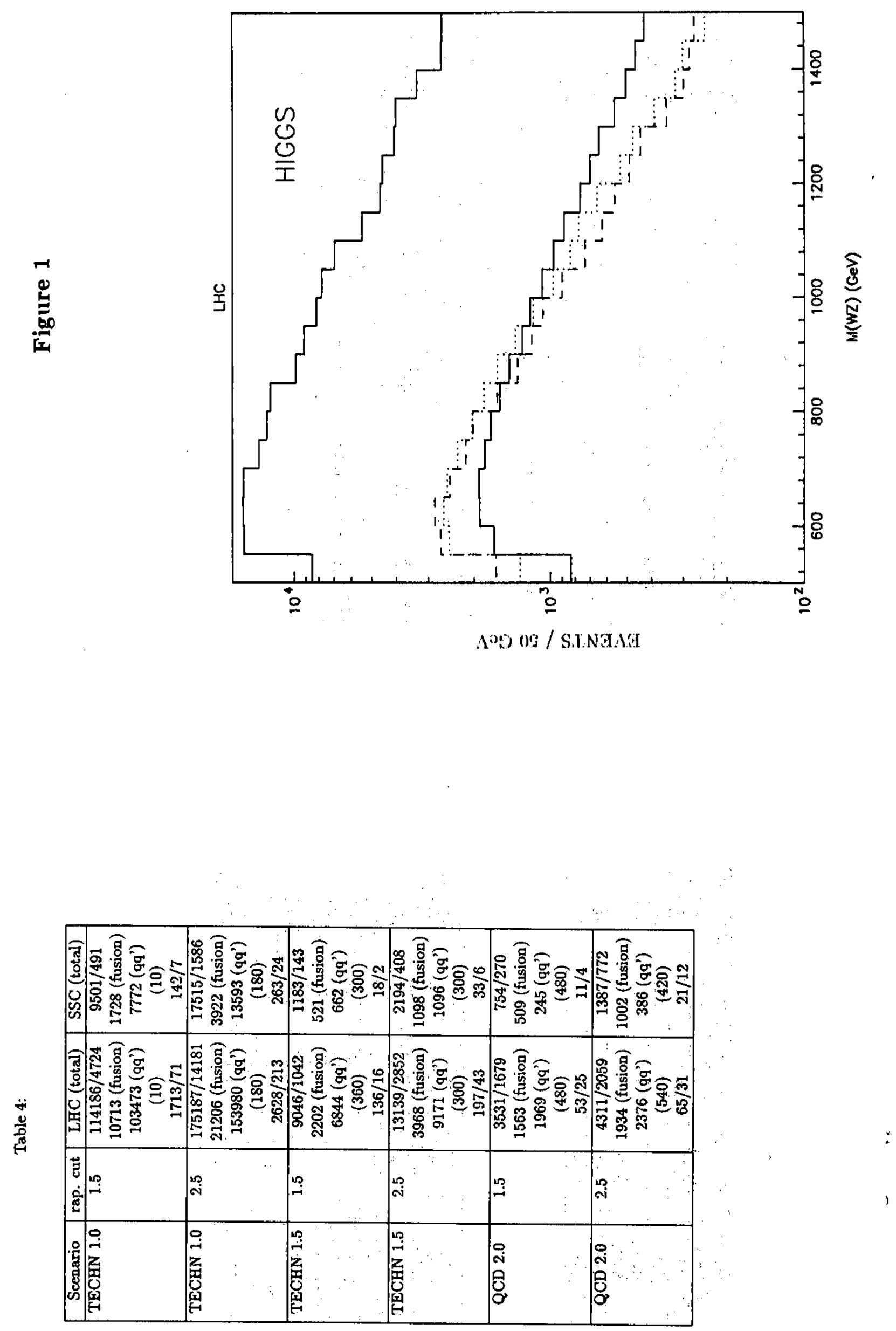


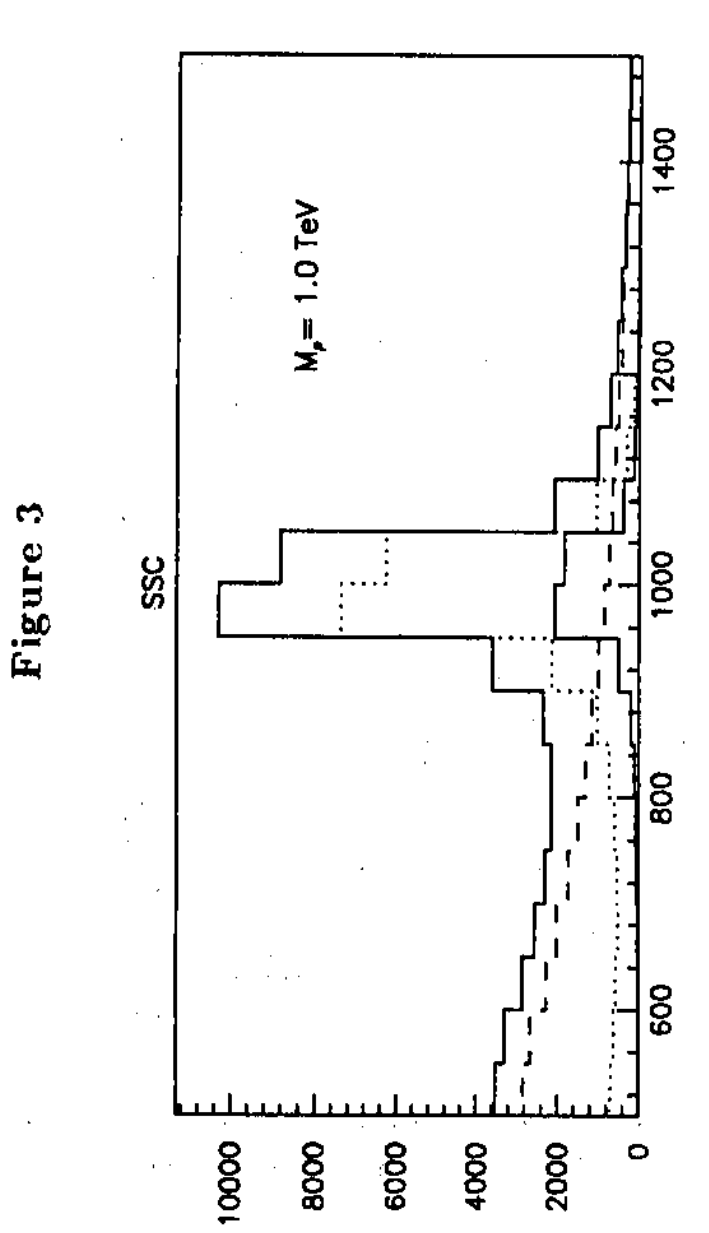

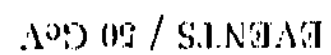

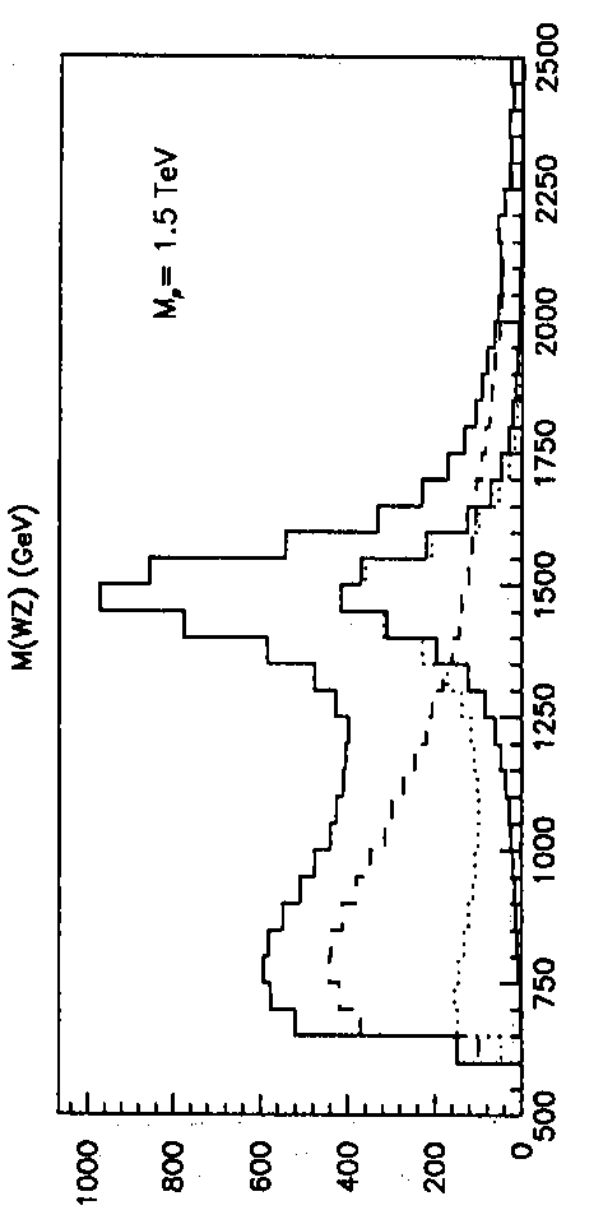

dos o / S.I.Nid.til

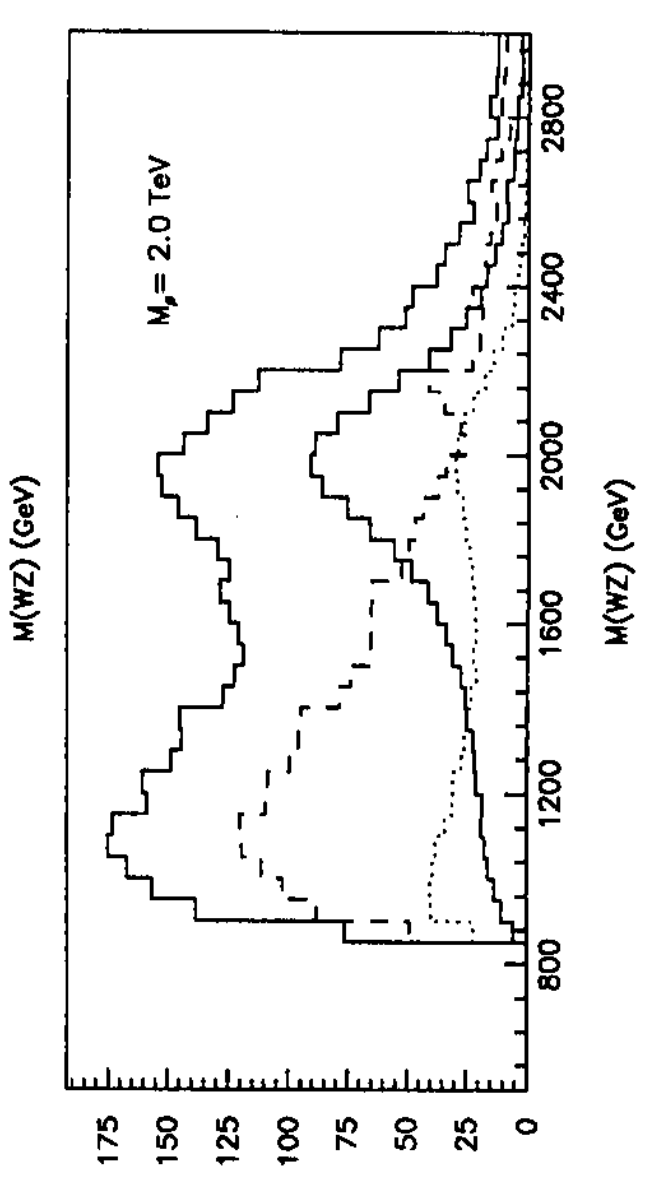

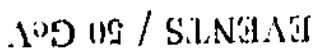

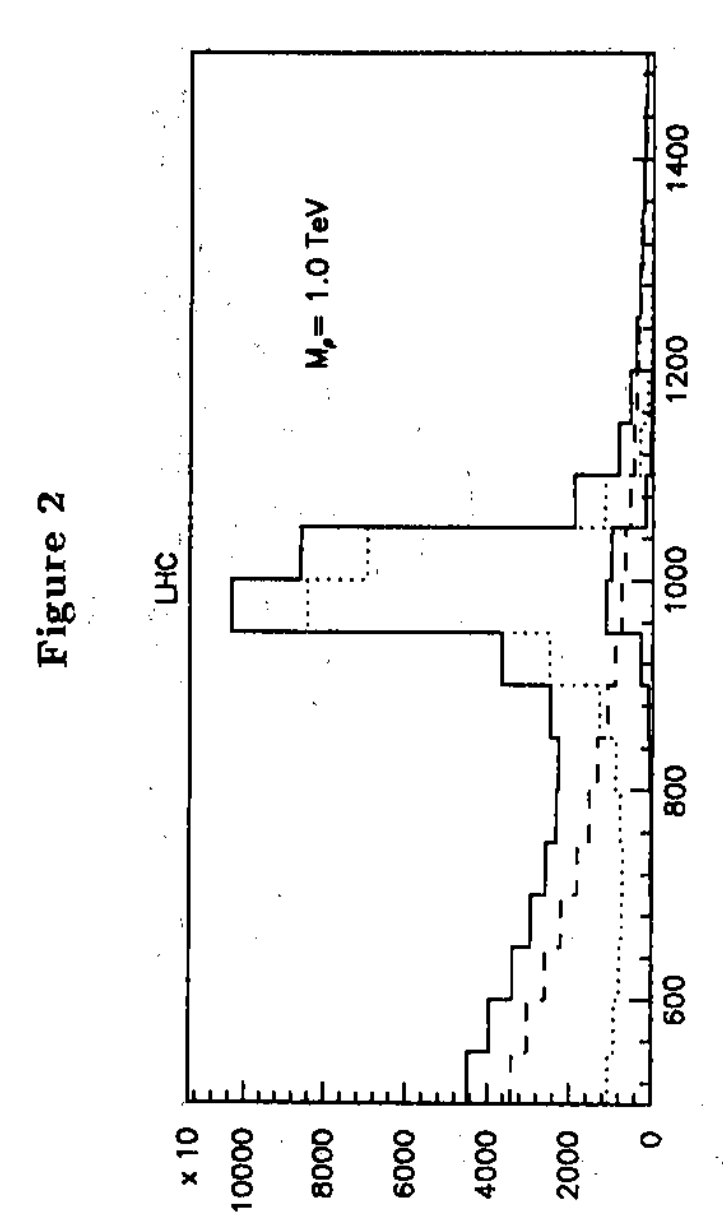

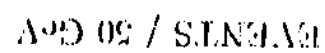

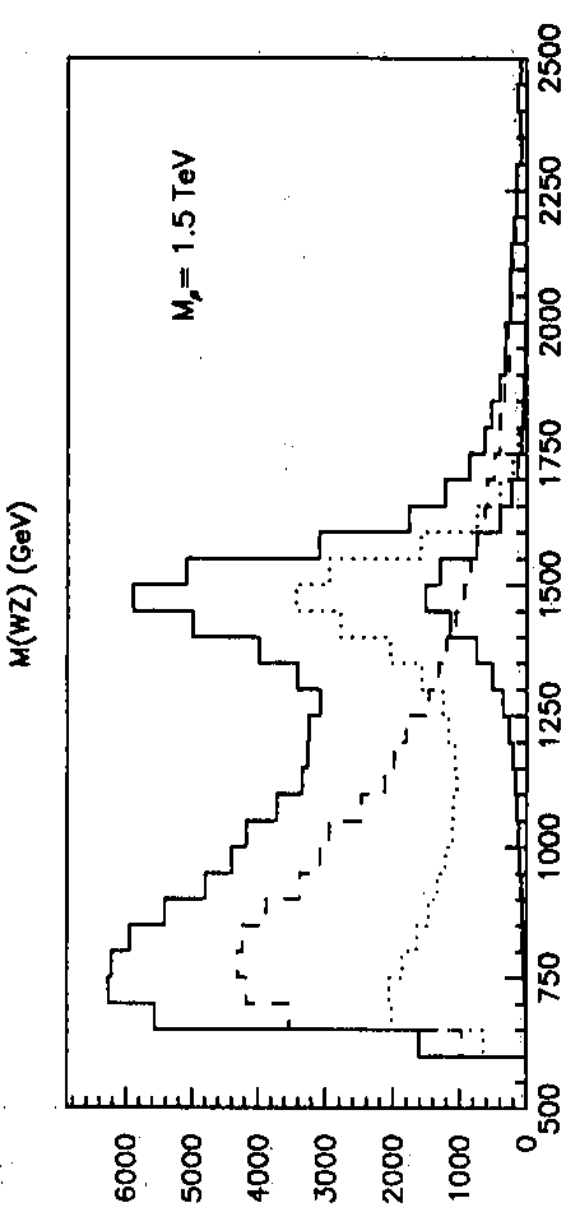

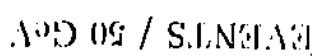

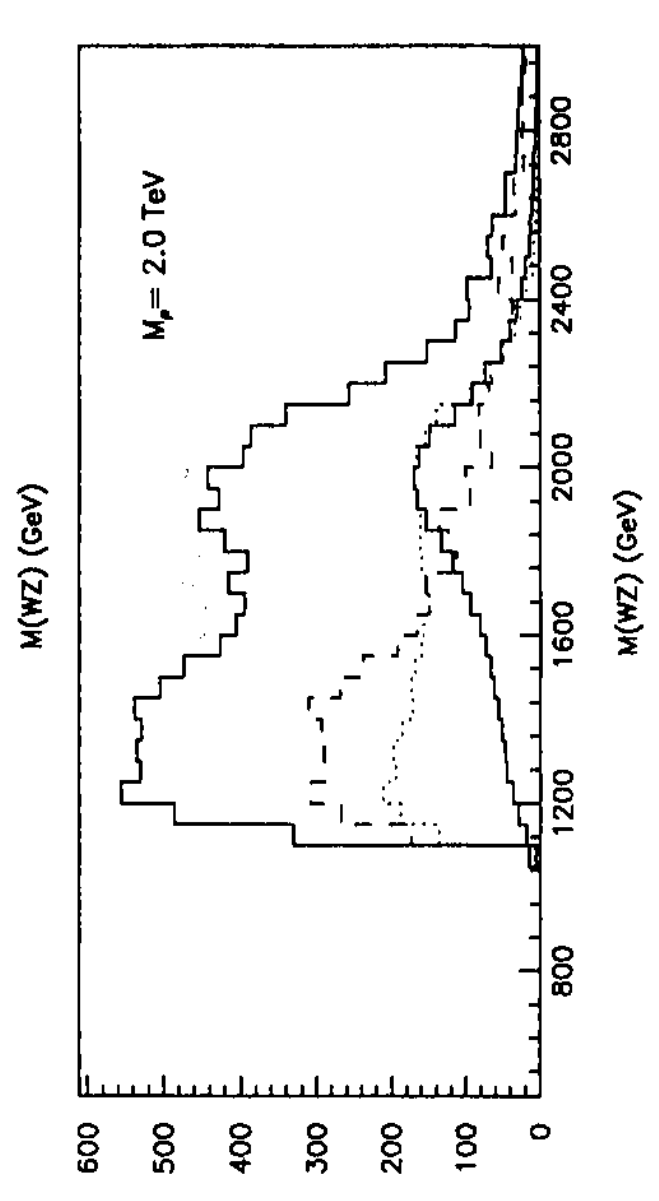

. IN) 
20

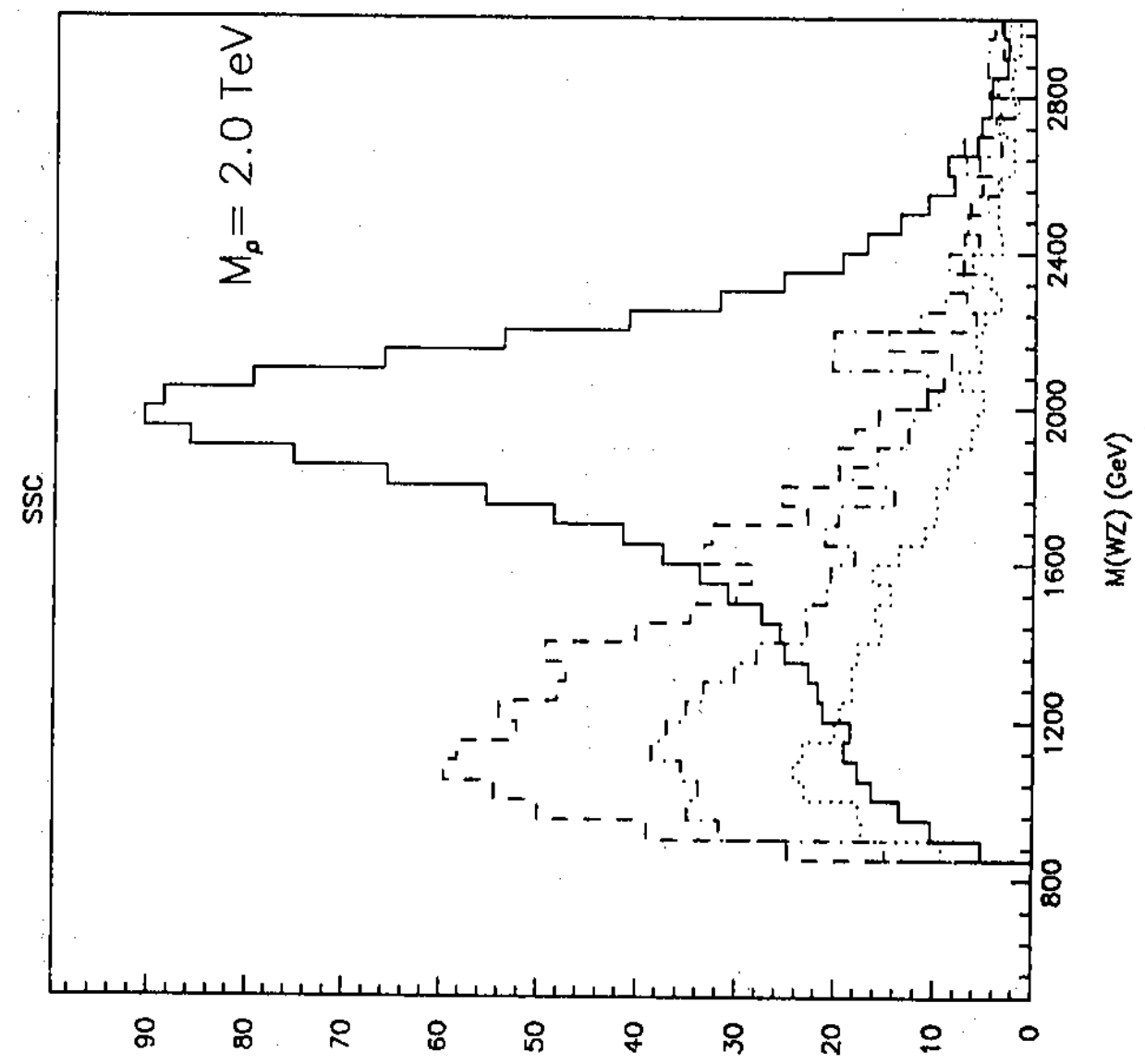

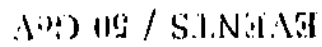

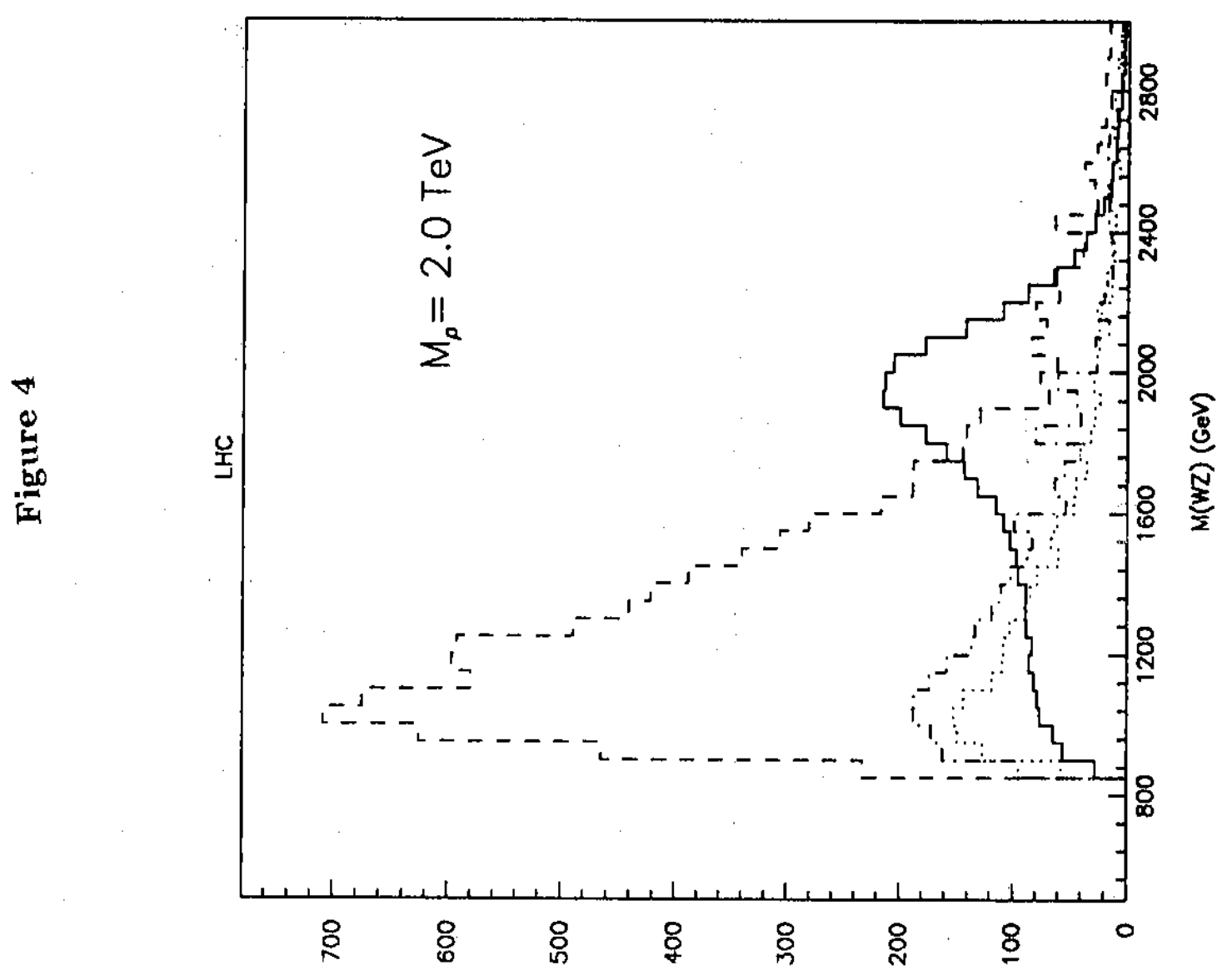

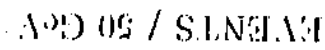

